\title{
Personality characteristics and bariatric surgery outcomes: a systematic review
}

\author{
Características de personalidade e desfechos em cirurgia bariátrica: uma \\ revisão sistemática
}

\author{
Suelen Bordignon, Mayra Juliana Galvis Aparício, Juliana Bertoletti, Clarissa Marceli Trentini*
}

\begin{abstract}
Introduction: Numerous studies have focused on psychological assessment of bariatric surgery candidates, aiming to identify which psychological variables, including personality characteristics, are related to successful surgical prognosis.

Objective: To analyze, by means of a systematic literature review, longitudinal studies that investigated personality traits and disorders as possible predictors of outcomes in bariatric surgery.

Method: PsycInfo, PubMed, and Scopus databases were searched for studies published between 2005 and 2015, using the keywords "bariatric" AND "personality." Quantitative longitudinal studies in English, Portuguese, or Spanish were selected for review if they assessed personality as an outcome predictor of BS in people aged 18 years or older.

Results: Sixteen articles were analyzed. The results of this review suggest that externalizing dysfunctions might be associated with less weight reduction, while internalizing dysfunctions appear to be associated with somatic concerns and psychological distress. The persistence dimension (of temperament in Cloninger's model) was positively associated with greater weight loss, while neuroticism (Five Factor Model) and the occurrence of personality disorders were not predictive of weight loss. Furthermore, the results indicate a tendency towards a reduction in personality disorders and neuroticism scores, and an increase in extroversion scores, after BS.
\end{abstract}

Conclusions: Assessment of personality characteristics, whether to identify their predictive power or to detect changes during the BS process, is important since it can provide grounds for estimating surgical prognosis and for development of interventions targeting this population.

Keywords: Personality, bariatric surgery, psychopathology, obesity.

\section{Resumo}

Introdução: A avaliação psicológica de candidatos à cirurgia bariátrica (CB) tem sido foco de inúmeros estudos com a finalidade de identificar quais as variáveis psicológicas, entre elas as características de personalidade, que se relacionam ao prognóstico cirúrgico.

Objetivo: Realizar uma revisão sistemática através de estudos longitudinais que investigaram traços e transtornos de personalidade como possíveis preditores de resultados em CB.

Método: Pesquisas nas bases de dados PsycInfo, PubMed e Scopus foram realizadas entre os anos de 2005 e 2015, considerando os descritores "bariatric" AND "personality". Foram incluídos estudos longitudinais quantitativos, em inglês, português ou espanhol, que avaliaram personalidade como preditor de desfecho em CB em população com 18 anos ou mais.

Resultados: Dezesseis artigos foram analisados. Os achados sugerem que alterações externalizantes podem estar associadas à menor perda de peso, enquanto que as alterações internalizantes a preocupações somáticas e distúrbios psicológicos; a dimensão persistência (temperamento no modelo de Cloninger) foi associada positivamente a maior perda de peso, enquanto que o fator neuroticismo (Modelo dos Cinco Fatores), e a existência de transtornos da personalidade não foram se mostraram preditivos de perda de peso. Ainda, os resultados indicam uma tendência à redução da prevalência de transtornos de personalidade e diminuição dos escores de neuroticismo e aumento dos escores de extroversão após a CB.

Conclusões: A avaliação das características de personalidade, como poder preditivo ou em suas alterações ao longo do processo da $\mathrm{CB}$, torna-se importante a medida que pode auxiliar no prognóstico cirúrgico e no planejamento de intervenções junto a essa população.

Descritores: Personalidade, cirurgia bariátrica, psicopatologia, obesidade.

\footnotetext{
* Instituto de Psicologia, Programa de Pós-Graduação em Psicologia, Universidade Federal do Rio Grande do Sul (UFRGS), Porto Alegre, RS, Brazil. Submitted Feb 15 2016, accepted for publication Jan 242017.

Suggested citation: Bordignon S, Aparício MJ, Bertoletti J, Trentini CM. Personality characteristics and bariatric surgery outcomes: a systematic review. Trends Psychiatry Psychother. 2017;39(2):124-134. http://dx.doi.org/10.1590/2237-6089-2016-0016
} 


\section{Introduction}

Bariatric surgery (BS) has come to be considered the most effective treatment for achieving sustained weight loss and improvements to the comorbidities associated with obesity (type II diabetes, cholesterolemia, cardiovascular diseases, and others).1,2 The number of BS procedures has increased over recent years, in line with the increasing rates of obesity all over the world. In Brazil, 72 thousand operations were performed in $2013^{3}$ and around 88 thousand in 2014. It is estimated that $10 \%$ of these were performed by the public health system. ${ }^{4}$ BS is indicated for patients who have undergone other weight loss treatments without success and who have a body mass index (BMI) greater than $40 \mathrm{~kg} / \mathrm{m}^{2}$ or BMI over $35 \mathrm{~kg} / \mathrm{m}^{2}$ and associated comorbidities. ${ }^{2}$

Traditionally, studies that assess BS outcomes have primarily focused on percentage of excess weight lost $(\% E W L)$, on weight reduction, or on BMI, comparing preoperative and postoperative data. However, other measures are also important for evaluation of the procedure's results, such as improvements in associated comorbidities and in quality of life, ${ }^{5}$ absence of complications after surgery, and no requirement for reoperation. ${ }^{6}$

While BS has proven to be an effective procedure for a large proportion of those who are treated, there is a subset of patients (around $20 \%$ ) who regain weight in the period from 18 months to 2 years after the

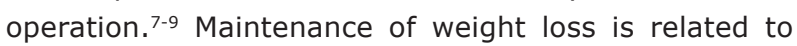
behavioral changes and the ability to implement lifestyle changes, to engagement in physical activities, changing dietary habits, and to development of strategies for coping and for emotional control unrelated to food. ${ }^{10}$

In addition to variables related to surgery, psychological and emotional factors play an important role in maintenance of long-term results. There is still no consensus in the literature on which elements help or hinder adaptation to the conditions created by surgery, or with relation to maintenance of weight and improved quality of life. ${ }^{9,11}$ An understanding of predictive variables would be of use to professionals who assess candidates for the procedure and could provide guidance for interventions in this population.

Among others, the following factors have been investigated as predictors of successful procedures: sociodemographic characteristics (e.g. age, sex, educational level), ${ }^{12}$ health variables (e.g. weight, clinical co-morbidities and psychopathologies), ${ }^{12,13}$ support network, coping, personal characteristics, and pathological traits (e.g. impulsivity, flexibility). ${ }^{11}$ Within mental health, studies focused on psychopathological features have attracted interest, especially because it has been found that there is a high prevalence of mental disorders in this population.

Rates of clinical disorders (excluding personality disorders [PD] and mental deficiency) exceed $40 \%$ among candidates for $\mathrm{BS}^{14-16}$ and psychiatric comorbidities are also evident. ${ }^{15,16}$ Depressive, bipolar, anxiety, and eating disorders stand out as the most prevalent. ${ }^{14,15,17}$ While there may be a higher incidence of mental disorders in the BS candidate population than in the general population, there is a body of work showing that symptoms of depression and anxiety, ${ }^{18-20}$ psychopathology in general, and eating compulsion 20 improve after the procedure has been conducted.

In a similar manner, the prevalence of PD has also been reported to be higher in the population of BS candidates than is found in the general population, with rates exceeding $20 \% .^{16,21,22}$ While these are elevated rates, there is no consensus in the literature with regards to associations between personality characteristics or psychopathologies and outcomes of BS. The psychological/ psychiatric practice of assessing candidates for BS needs empirical evidence to support the indications of which patients should be given the procedure, and also to identify factors that represent potential risks to patients.

Personality disorders are characterized by the presence of inflexible, chronic, and pervasive patterns that are stable over time and compromise people's interpersonal functioning. ${ }^{23}$ The current Diagnostic and Statistical Manual of Mental Disorders (DSM-5) 23 offers two ways to classify $P D$. The ten disorders listed in the previous version of the manual were maintained, and an alternative, hybrid model for personality assessment was also proposed. The new model offers the possibility of a multidimensional assessment of maladaptive personality traits and a clinical classification comprising seven disorders, one of which is personality disorder - trait specified, in which pathological personality traits are identified.

In addition to details of the psychopathologies of PD, the literature also covers theories of personality development, the healthy and adaptive characteristics of personality, and descriptive models of its dimensions or structures. A psychobiological model proposed by Cloninger et al. ${ }^{24}$ offers an interpretation of the neurobiological bases and genetic antecedents of personality. It comprises four dimensions of temperament (novelty seeking, harm avoidance, reward dependence, and persistence) which describe differences between the ways that people deal with everyday situations, in particular with novelty, danger, punishment, or reward, and three dimensions of character (self-directedness, cooperativeness, and selftranscendence), which exhibit the influence of learning and can be regulated by the environment. 
One of the most widely-used, validated, and replicated models of personality structure is the FiveFactor Model (FFM). ${ }^{25}$ Its five domains are neuroticism, extraversion, agreeableness, conscientiousness, and openness to experience. The personality traits assessed by the five domains are broad and comprehensive, and everybody can be placed within the spectrum for each of the dimensions. ${ }^{25}$

Although personality characteristics are considered stable and consistent over time, this definition does not imply that there are no changes to the dimensions of traits. Studies have demonstrated that personality traits change in a normative manner within the population, and may be triggered by biological issues (e.g. onset of adolescence) or even by social situations (e.g. professional life). ${ }^{26,27}$ Since BS is a major procedure and significantly changes patients' lives, a need has been identified to determine whether this procedure may also be a factor in changing personality characteristics.

There are other interpretations and models of personality. However, the models listed above are those that have been used in the greatest numbers of studies of the BS patient population. In general, studies in this population evaluate changes to personality profiles and characteristics that are liable to change after the surgery or attempt to identify variables that are predictive of better or worse outcomes after the procedure (which may be in relation to weight loss and maintenance, metabolic abnormalities - associated comorbidities, quality of life, compliance with medical guidance, or other elements).

The objectives of this systematic review were to analyze and summarize the results of studies that have evaluated PD or traits/profiles in patients who have undergone BS. Additionally, an attempt was made to understand the relationships between personality traits or disorders that are present preoperatively and outcomes during the postoperative period and changes to characteristics or prevalence of PD between preoperative and postoperative periods.

\section{Method}

This systematic review was conducted using the PRISMA criteria. ${ }^{28}$ Articles describing longitudinal studies were selected on the basis of two criteria: a) they assessed personality traits or disorders as predictors of outcomes of bariatric surgery, or b) assessed changes to personality traits or changes in the prevalence of PD between pre-surgical and post-surgical periods. PsycInfo, PubMed, and Scopus databases were consulted on October 5, 2015, using the keywords "bariatric" AND "personality". The search criterion adopted for all three databases was these keywords present in any fields for complete articles published from 2005 to 2015.

A database was constructed containing the abstracts and duplicate articles were excluded. Abstracts were assessed by two independent judges and when they did not agree a third judged decided whether the abstract in question would be included on the basis of the previously defined inclusion criteria. When analyzing abstracts, studies were chosen for inclusion that: a) were longitudinal; b) assessed personality prior to surgery and related the findings to an outcome after surgery; c) investigated changes in traits or prevalence of PD; d) were empirical; e) were written in English, Spanish, or Portuguese and, f) had study populations aged over 18 . The strategy for abstract selection is illustrated in Figure 1.

The initial search returned 1224 abstracts, 61 published in journals indexed on PsycInfo, 364 on PubMed, and 799 on Scopus. After exclusion of duplicated abstracts, 30 articles met the eligibility criteria and their full texts were read. On reading, it was found that 13 did not meet at least one criterion and the data of interest for this review were the same in two articles, ${ }^{16,29}$ so the one with the earlier publication date was included and the later article was excluded ${ }^{29}$ (Figure 1 ). At the end of this process, 16 articles remained for analysis (one including an errata).

Data were extracted by the lead author and the process employed was discussed by the first three authors and supervised by the last author. The data extracted were related to the study samples (number of participants, mean age, BMI before surgery), personality assessment instruments, pre-surgical and post-surgical assessment times, outcome variable used for analysis of the results of BS (related to the predictive personality variables), and main results related to the objectives of this review.

All 16 articles included were analyzed to assess their methodological quality. The evaluation was conducted according to criteria employed previously by GarcíaLlana et al. ${ }^{30}$ (adapted from criteria proposed by Berra et al. ${ }^{31}$ ), and the results are shown in Table 1.

\section{Results and discussion}

After selecting articles that met all of the inclusion criteria, 16 articles remained to be analyzed. Description and discussion of the findings of the review will begin with an analysis of the general characteristics of the studies selected (the samples studied and points in time at which participants were assessed). The results reported in the articles will then be presented and analyzed, first covering studies that investigated personality traits or disorders as predictors of outcomes, and then covering 
those that assessed changes in personality traits or disorders over time.

\section{General description of articles assessed}

The samples assessed in the studies varied in terms of number of participants from a maximum of $859^{34}$ to a minimum of $30 .{ }^{35}$ Among studies that stated the sex of participants, the samples were predominantly female, which is the case in the majority of studies in this area. ${ }^{42-45}$ In addition to the literature stating that women seek health care more than men, it is also important to take into account the World Health Organization data showing that the prevalence of obesity is higher among females than among males. ${ }^{46}$

The age of participants ranged from 18 to 65 years, although 12 studies ${ }^{11,21,22,32-39,41}$ did not provide this data. Similarly, BMI before surgery varied from $30.6 \mathrm{~kg} / \mathrm{m}^{2}$ to $108.7 \mathrm{~kg} / \mathrm{m}^{2}$, and 13 articles ${ }^{11,12,21,22,29,32,33,35-39,41}$ did not provide this information. While both these variables (age and BMI) varied widely in the sample, the majority of articles only mention mean and standard deviation, which could compromise readers' understanding of the data. Along the same lines, it should be considered that different degrees of obesity interfere differently in distinct aspects of life, whether economic (spending on treatment), physical (locomotion, restrictions to activities), psychological (symptoms of anxiety, depression, and eating disorders), medical (comorbidities, life expectancy), or social (prejudice, discrimination, etc). ${ }^{47}$

With regard to the type of surgery performed, the majority of these studies (10 out of 16 ) refer to Roux-en-Y Gastric Bypass, ${ }^{12,21,22,29,32-34,36,37,39}$ among other procedures. The second most common procedure was Adjustable Gastric Band surgery (in six studies). ${ }^{11,14,34,38,40,41}$

Only two studies specified the period during which preoperative psychological/psychiatric assessment was conducted, ${ }^{14,21}$ ranging from 1 to 2 months before surgery. Postoperative assessments were conducted at times ranging from 1 to 48 months after the procedure and the majority (11 studies) conducted an evaluation 12 months after the procedure. Three studies ${ }^{12,33,40}$ assessed patients beyond 12 months, just one of which conducted follow-up at 36 and 48 months. ${ }^{40}$ It is notable that in the context of personality assessment, few studies conducted long-term follow-up of these patients, especially beyond 18 months, when the likelihood of weight gain is higher. ${ }^{48}$

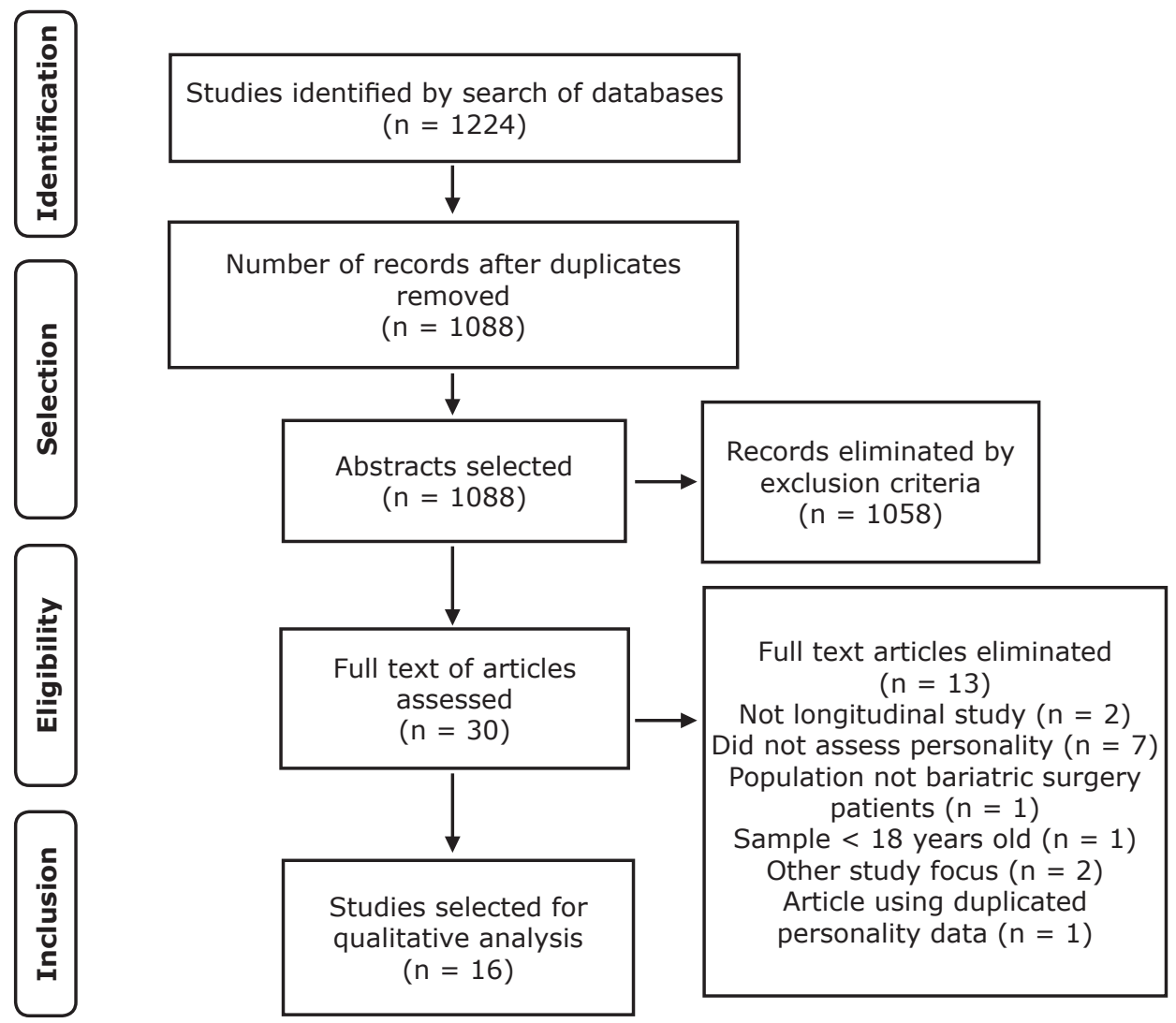

Figure 1 - Flow diagram illustrating selection of articles for PRISMA systematic review. 
The majority of articles (13 out of 16) focused on assessment of personality characteristics or PD as predictors of surgical outcomes, with fewer studies investigating changes in personality profile over time. Of the studies analyzed, five ${ }^{12,14,21,33,41}$ conducted analyses using the Cloninger et al. psychobiological model, ${ }^{24}$ two ${ }^{11,38}$ based assessment on the FFM, ${ }^{25}$ four ${ }^{14,21,22,40}$ assessed PD, and a further three $21,22,40$ analyzed psychopathological characteristics of personality. One article $^{21}$ investigated both PD and temperament and another ${ }^{11}$ conducted a predictive analysis of personality characteristics and changes over time.

Table 1 lists the results of the analysis of the articles' methodological quality. The mean score for the articles was 10.1 points (high quality), varying from 7 to 12 points. Three articles were classified as medium quality ( 5 to 8 points) and 13 were classed as high quality ( 9 to 12 points). It is worth highlighting that all of the articles analyzed were classified as medium or high, indicating good overall methodological quality.

\section{Personality traits or disorders (preoperative) and surgical outcomes}

Thirteen of the 16 studies assessed focused on relating postoperative outcomes to personality traits or disorders present in the preoperative period. Three of these assessed PD in patients who underwent BS (one of them with the intention of controlling PD as a potential confounding variable), ${ }^{21}$ four analyzed psychopathological characteristics, five focused on personality assessment according to the Cloninger et al. personality model, ${ }^{24}$ and two used the FFM. ${ }^{25}$ Table 2 lists data for the samples studied in the articles reviewed. In turn, Table 3 lists the main findings related to the outcome of $B S$ in relation to personality characteristics or PD.

The BS outcome variable most frequently analyzed in the studies reviewed was weight reduction (Table 3). Three studies attempted to detect relationships that would predict weight loss and/or treatment compliance variables according to presence of PD. Two of these articles ${ }^{21,22}$ did

Table 1 - Evaluation of methodological quality of articles analyzed for review

\begin{tabular}{|c|c|c|c|c|c|c|c|c|c|c|c|c|c|c|}
\hline Reference & 1 & 2 & 3 & 4 & 5 & 6 & 7 & 8 & 9 & 10 & 11 & 12 & Total & Quality \\
\hline Agüera et al. ${ }^{12}$ & + & + & + & - & - & + & + & + & + & - & + & + & 9 & High \\
\hline Marek et al. ${ }^{32}$ & - & + & + & + & + & + & + & + & + & + & + & + & 11 & High \\
\hline de Panfilis et al. ${ }^{21}$ & - & + & + & + & + & + & + & - & + & - & + & + & 9 & High \\
\hline Gordon et al. ${ }^{33}$ & + & + & + & + & + & - & + & + & + & + & + & + & 11 & High \\
\hline Marek et al. ${ }^{34}$ & - & - & + & + & + & - & + & + & + & + & + & + & 9 & High \\
\hline da Silva \& Maia ${ }^{35}$ & - & + & + & + & + & + & + & + & + & + & + & + & 11 & High \\
\hline Capuron et al. ${ }^{36}$ & + & + & + & + & + & + & + & + & + & + & + & + & 12 & High \\
\hline Lier et al. ${ }^{29}$ & + & + & + & + & + & + & + & - & + & + & + & + & 11 & High \\
\hline Belanger et al. ${ }^{37}$ & - & + & + & - & - & + & + & - & + & + & + & + & 8 & Medium \\
\hline Canetti et al. ${ }^{38}$ & + & + & + & + & + & + & + & + & + & + & + & + & 12 & High \\
\hline van Hout et al. ${ }^{11}$ & - & + & + & + & NA & + & + & + & + & + & + & + & 10 & High \\
\hline Bannen et al. ${ }^{39}$ & - & + & - & + & + & - & - & - & + & + & + & + & 7 & Medium \\
\hline Kalarchian et al. ${ }^{22}$ & + & + & + & + & + & + & + & + & + & + & + & + & 12 & High \\
\hline Pontiroli et al. ${ }^{40}$ & + & + & + & - & - & + & + & - & + & + & + & - & 8 & Medium \\
\hline Leombruni et al. ${ }^{41}$ & + & + & + & + & - & + & + & + & + & + & + & + & 11 & High \\
\hline de Panfilis et al. ${ }^{14}$ & - & + & + & + & NA & + & + & + & + & + & + & + & 10 & High \\
\hline
\end{tabular}

$\mathrm{NA}=$ not applicable

Criteria assessed, as per Garcia-Llana et al..$^{30}$

Study design and sample selection: 1) Describes inclusion and exclusion criteria for participants; 2) Specifies the sample selection methods; 3) Specifies the study design; 4) Provides numbers of potentially eligible participants and/or those initially selected and/or those who accepted and/or those who actually took part; 5) If groups were compared, provides information in point 4 for each group.

Definitions and assessment of variables studied: 6) Clearly defines the variables studied; 7) Uses validated instruments or guidelines for the principal variables.

Method and analysis of the data: 8) Samples assessed contain at least 30 participants; 9) Statistical tests used are specified; 10) Lost participants and/or data are dealt with correctly (or the text at least states that the quality of data was reviewed before statistical analysis).

Quality of results and discussion: 11) Results are clearly described according to the study objectives; 12) The discussion considers practical implications of the results and potential benefits for participants.

Quality assessment: low, 1-4 points; medium, 5-8 points; high, 9-12 points. 
not detect a correlation between PD and weight reduction at 12 months and the other ${ }^{40}$ found a negative association between narcissistic PD and weight loss and adherence to treatment (diet, exercise, percentage attendance at consultations). It is clear that although these studies conducted their assessments using the same instruments, their results are contradictory. It is worth considering that their samples are of limited size and studies with larger samples need to be conducted.

The difficulty involved in conducting such studies is understandable in view of the need for large samples, since the estimated prevalence of any type of PD in the general population is $9-15 \%$ (DSM-5). It should also be taken into consideration that the prevalence of PD in clinical samples of candidates for BS appears to be higher, ${ }^{49}$ which has also been pointed out in the studies analyzed in this review. ${ }^{21,22,29}$ This indication raises concerns about preoperative assessment in relation to presence of pathology and the postoperative result in these patients.

Among studies that used the Minnesota Multiphasic Personality Inventory (MMPI), two ${ }^{37,39}$ used version MMPI-2 ${ }^{50}$ and the other two ${ }^{32,34}$ used version MMPI$2 \mathrm{R}^{51}$ (the restructured version). The studies employing the MMPI-2R only used the substantive scales for investigation of relationships with outcomes, whereas those that employed the MMPI-2 used both the validity scales and the clinical scales. The outcome variables assessed in the studies that used the MMPI-2R were weight reduction in both, non-adherence in one study, and somatic complaints, psychological distress and maladaptive eating behavior in the other.
The externalizing dysfunctions domain is related to poor control of impulses and low tolerance of frustration ${ }^{52}$ and it was found that this domain had a negative association with weight reduction at 12 months and a positive association with maladaptive eating behavior at 3 months. According to the same findings, a compulsive personality profile was also negatively associated with weight reduction. ${ }^{37}$ Although the authors did not describe what they considered maladaptive eating behavior to comprise (it is unclear whether they are referring, for example, to non-compliance with nutritional guidance, to psychopathological eating behavior, bulimia, etc.) and the instrument employed to assess it is unpublished, it nevertheless appears that patients who exhibited dysfunctions in the externalizing domain were already exhibiting unhealthy eating behavior at 3 months and were more likely not to attend consultations 12 months after the procedure.

With regard to this, there are reports in the literature that eating compulsion present at preoperative assessment is predictive of eating compulsion during the postoperative period, ${ }^{53}$ although there is a tendency for the prevalence of eating disorders to reduce after surgery. ${ }^{54}$ However, there is not yet consensus between studies with regard to predicting weight loss using eating disorders at preoperative assessment as predictive variables. ${ }^{45,53-55}$ Additional studies that evaluate associations between maladaptive eating behavior and weight loss over the long term are needed to address this issue.

While externalizing dysfunctions appear to be more related to less weight loss and to maladaptive eating behavior, internalizing dysfunctions exhibited associations

Table 2 - Samples in studies that assessed relationships between outcomes of bariatric surgery and personality characteristics or disorders

\begin{tabular}{|c|c|c|c|c|}
\hline Article & Sample & Mean age at T0 (SD) & Mean BMI at TO (SD) & Assessment times (in months) \\
\hline de Panfilis et al. ${ }^{21}$ & 49 & $37.8(9.9)$ & $46.4(6.7)$ & T0: $1-2 ; \mathrm{T} 1: 12$ \\
\hline Kalarchian et al. ${ }^{22}$ & 207 & $45.8(9.5)$ & $51.4(9.6)$ & TO: NI; T1: 6 (4 to 8 ); \\
\hline Pontiroli et al. ${ }^{40}$ & 172 & $40.7(0.81)$ & $44.9(0.51)$ & $\begin{array}{c}\text { T0: NI; T1: } 12 ; \text { T2: } 24 ; \text { T3: 36; } \\
\text { T4: } 48\end{array}$ \\
\hline Marek et al. ${ }^{32}$ & 498 & $46.44(11.58)$ & $47.14(8.23)$ & T0: NI; T1: 12 \\
\hline Marek et al. ${ }^{34}$ & 859 & $46.33(11.68)$ & $49.94(11,05)$ & T0: NI; T1: $1 ; \mathrm{T} 2: 3$ \\
\hline Belanger et al. ${ }^{37}$ & 143 & $43.24(9.7)$ & $49.43(9.13)$ & T0: NI; T1: $1 ;$ T2: $2 ;$ T3: $3 ;$ T4: 6 \\
\hline Bannen et al. ${ }^{39}$ & $\begin{array}{l}110 \text { ( } 6 \text { challenging-to- } \\
\text { manage patients } * \text { ) }\end{array}$ & NI & NI & NI \\
\hline Agüera et al. ${ }^{12}$ & 139 & $40.6(10.3)$ & $46.3(6.4)$ & $\begin{array}{c}\text { T0: NI; T1: } 3 ; \text { T2: } 6 ; \text { T3: } 12 ; \text { T4: } \\
18 ; \text { T5:24 }\end{array}$ \\
\hline Gordon et al. ${ }^{33}$ & 333 & $35.4(9.5)$ & $43.3(4.8)$ & $\begin{array}{c}\text { T0: NI; T1: 6; T2: } 12 ; \text { T3: } 24 ; \\
\text { T4: CO }\end{array}$ \\
\hline Leombruni et al. ${ }^{41}$ & 38 & $39.8(9.92)$ & $43.52(5.52)$ & T0: NI; T1: 6 \\
\hline de Panfilis et al. ${ }^{14}$ & 35 & $41.2(8.3)$ & $45.5(4.8)$ & T0: 1; T1: 12 \\
\hline Canetti, et al. ${ }^{38}$ & 44 & $34.2(10.0)$ & $45.1(7.7)$ & T0: NI; T1: 12 \\
\hline van Hout et al. ${ }^{11}$ & 112 & $38.8(8.3)$ & $45.3(5.1)$ & T0: NI; T1: 24 \\
\hline
\end{tabular}

$\mathrm{SD}=$ standard deviation; $\mathrm{BMI}=$ body mass index; $\mathrm{CO}=$ clinical observation; NI = information not provided; $\mathrm{T} 0=$ preoperative assessment; $\mathrm{T} 1-\mathrm{T} 5$ = postoperative assessments

* Patients who had 2 of the following criteria: did not attend consultations, did not take supplements, did not follow eating guidance, had physical complications, were readmitted. 
Personality and bariatric surgery - Bordignon S et al.

Table 3 - Main findings of studies that assessed relationships between outcomes of bariatric surgery and personality characteristics or disorders

\begin{tabular}{|c|c|c|c|}
\hline Article & $\begin{array}{l}\text { Personality } \\
\text { assessment }\end{array}$ & Variable outcome & Main findings \\
\hline de Panfilis et al. ${ }^{21}$ & $\begin{array}{l}\text { SCID-II, } \\
\text { temperament } \\
\text { scales of the TCI }\end{array}$ & $\% W L$ & 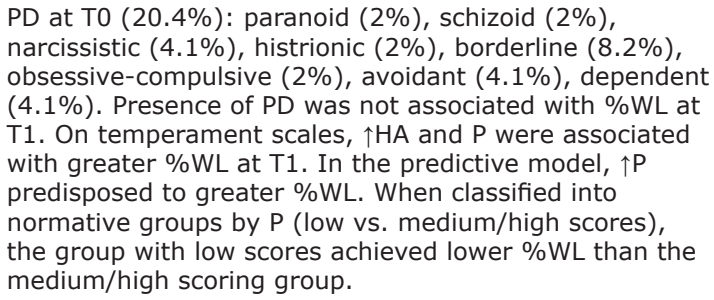 \\
\hline
\end{tabular}

Kalarchian et al. ${ }^{22}$ SCID-II

Pontiroli et al. ${ }^{40}$ SCID-II

Marek et al. ${ }^{32} \quad$ MMPI-2-RF

Marek et al. ${ }^{34}$

MMPI-2-RF

SC, PSD, and MAEB

$\% W L$, \%EWL, non-adherence (failure to attend consultation) $\%$ EWL

Weight loss, compliance with diet, rules, and exercises, percentage attendance at consultations medium/high scoring group.

$28.5 \%$ exhibited at least one PD at T0. PD at T0 was not related to change in weight at $\mathrm{T} 1$.

PD at T0 (11.7\%): narcissistic $(6.9 \%)$, histrionic $(1.7 \%)$, antisocial $(1.2 \%)$, passive-aggressive $(1.2 \%)$, dependent $(0.6 \%)$. Narcissistic PD had a negative association with weight loss at T1, T2, and T3 and with compliance with diet and exercises, overall compliance, and attendance at consultations. In a predictive model, narcissistic PD was associated with weight loss at $\mathrm{T} 1$.

$\uparrow B X D, R C 9$, aggression and aggression-revised (T0) were associated with lower \%WL. $\uparrow B X D, R C 4$, JBP and Disc-R, substance abuse, and aggression (TO) were associated with non-adherence. In predictive models, lower \%WL was associated with $\uparrow B X D, R C 9$, and aggression and nonadherence with $\uparrow B X D, R C 4, J B P$, and Disc-R.

Somatic concerns scales and EID (TO) were correlated with SC at T1 and T2. EID measures were associated with SC at T2 and with PSD at T1 and T2. EID and BXD scales were associated with MAEB at T3. Measures in the domain thought dysfunction and some measures of somatization were associated with MAEB at T3.

MMPI-2: $\uparrow \mathrm{K}$ was predictive of less BMI reduction at all assessment times. MCM-II: in a 1-factor predictive model, $\downarrow \mathrm{C}$ was predictive of greater BMI reduction (T1). In a 2-factor model, $\downarrow C$ and $\uparrow$ schizotypal were predictors of $\mathrm{BMI}$ reduction at $\mathrm{T} 2$ and $\mathrm{T} 4$ and $\downarrow \mathrm{C}$ and $\uparrow$ schizoid were predictors of BMI reduction at T3.

Challenging-to-manage patients had $\uparrow$ VRIN, F, Fb, and Fp and $\downarrow \mathrm{K}$ and $\mathrm{S}$ (validity scales) and $\uparrow$ depression and paranoia (clinical scales).

patients*

WL ( $50 \%$ or greater of EW) and metabolic results

$\%$ EWL (weight at T0 postoperative weight) $\times 100 /$ EW TO

BMI, vomiting, and bulimic behavior

BMI reduction: $\mathrm{BMI}$ at t0 - BMI at $\mathrm{t} 1$

WL, QoL, mental health, psychological stress, and wellbeing

EWL, excess BMI lost, and QoL $\uparrow C$ was associated with losing more than $50 \%$ of EW and with \%EWL (predictive model), but was not predictive of comorbidities during the postoperative period.

$\downarrow P$ associated with less WL at T3 and posterior consultation. $\mathrm{P}$ and NS were positively and ST was negatively correlated with WL at T2 and T3. In CO beyond 24 months, $\mathrm{P}$ remained predictive of greater \%EWL.

Greater WL was associated with $\uparrow S D$. Patients with $\uparrow S T$ had a stronger tendency towards less vomiting ( $\leq 1$ per week).

$\mathrm{P}$ had a positive association with reduction in BMI.

$\mathrm{N}$ did not predict any of the variables studied.

Did not predict weight or BMI reduction or improved QoL. van Hout et al. ${ }^{11}$ DPQ ( $\mathrm{N}$ and SA scales)

$\uparrow=$ higher scores; $\downarrow=$ lower scores; \%WL = percentage weight lost; \%EWL = percentage excess weight lost; SD = self-directedness; SA = social anxiety; ST = self-transcendence; $\mathrm{NS}=$ novelty seeking; $\mathrm{BXD}=$ behavioral/externalizing dysfunction; $\mathrm{C}=$ compulsive; MAEB = maladaptive eating behavior; Disc- $\mathrm{R}=$ disconstraint-revised; $\mathrm{DPQ}=$ Dutch Personality Questionnaire; PSD = psychological distress; $\mathrm{EID}=$ emotional/internalizing dysfunction; HA = harm avoidance; $\mathrm{EW}=$ excess weight; $\mathrm{F}=$ infrequency; $\mathrm{Fb}=$ final test infrequency ; $\mathrm{Fp}=$ infrequent psychopathology; $\mathrm{BMI}=$ body mass index; $\mathrm{JBP}=$ juvenile behavior problems; $\mathrm{K}=$ defensiveness; MCM-III = Millon Clinical Multiaxial Inventory-III; MMPI-2RF = Minnesota Multiphasic Personality Inventory - Restructured Form; $\mathrm{N}=$ neuroticism; NEO-PI-R = NEO Personality Inventory-Revised, NI = information not provided; $\mathrm{CO}=$ clinical observation; $\mathrm{P}=$ persistence; $\mathrm{WL}=$ weight lost; $\mathrm{SC}=$ somatic concerns; $\mathrm{QOL}=$ quality of life; RC4 = antisocial behavior; RC9 = hypomanic activation; $\mathrm{S}=$ superlative self-presentation ; SCID-II = Structured Clinical Interview for DSM-IV Axis II Personality Disorders; T0 = preoperative assessment; T1-T5 = postoperative assessments; TCI = Temperament and Character Inventory; PD = personality disorders; VRIN = variable response inconsistency.

* Patients who had 2 of the following criteria: did not attend consultations, did not take supplements, did not follow eating guidance, had physical complications, were readmitted. 
with somatic complaints and psychological distress. Once more, the authors do not describe the outcome variables (somatic complaints and psychological distress), but it appears to make sense that internalizing dysfunctions, i.e. those that are expressed internally and are normally characterized by sadness, anxiety, withdrawal, excessive worrying, and fears, ${ }^{56}$ would be associated with emotional distress and concerns.

Two studies 37,39 diverged in terms of the validity scales. Belanger et al. found an association between higher $\mathrm{K}$ scores (indicative of greater resistance to revealing personal information) and less BMI reduction at all assessment times, while Bannen et al. ${ }^{39}$ found a negative association between both this factor and $\mathrm{S}$ (superlative self-presentation) and belonging to a group of challenging-to-manage patients. Bearing in mind the characteristics associated with the other validity scales, it is possible that hypersensitivity to criticism, difficulties solving problems, and higher scores for stress and depressive symptomology may be associated with worse compliance with guidance and attendance at follow-ups during the postoperative period. ${ }^{39}$

Persistence was the factor of temperament that exhibited the greatest consistency with weight loss during the postoperative period, detected by three out of five articles that assessed personality using the Cloninger psychobiological model. ${ }^{14,21,33}$ The persistence factor relates to persistence in an action, despite an absence of reinforcement. In view of the populations being studied - people who have undergone BS - it is understandable that adherence to physicians' instructions, nutritional guidance, and advice on physical activity in the face of reductions in weight loss over time is essential for achieving the long-term objectives.

It has been documented that the initial weight loss, together with external reinforcement (compliments, comments), is in itself highly gratifying for patients. ${ }^{48}$ However, these reinforcements are attenuated over time and it is possible that the persistence personality trait helps in maintenance of the behavior acquired, as was seen in a study that indicated that even 24 months after the procedure this trait remains predictive of weight loss. ${ }^{33}$

With reference to other factors of temperament, in isolation, two articles found positive correlations between novelty seeking ${ }^{33}$ and harm avoidance ${ }^{21}$ and weight loss at 12 months. The factor reward dependence was not correlated with any of the outcomes in any of the articles reviewed.

Among the dimensions of character, self-transcendence was identified in two articles as a predictor of the outcome of surgery. In one of them ${ }^{33}$ it was associated with lower weight loss at 12 and 24 months and in the other ${ }^{41}$ with a lower likelihood of vomiting at 6 months.
Neither study found associations with weight loss at 6 months. While these results are not contradictory, they are in opposite directions. Considering that the sample in one of these studies was small ${ }^{41}$ and that other articles ${ }^{12,14,21}$ did not detect these associations, it can be concluded that there is no consensus in relation to self-transcendence and outcomes of weight reduction or bulimic behavior/vomiting.

Just two articles associated the other two factors that comprise the Character dimension of the Cloninger model with weight loss, cooperativeness in one ${ }^{12}$ and self-directedness in another. ${ }^{41}$ These characteristics of character do not appear to be determinants of weight loss in patients who underwent BS.

Two studies investigated the characteristics of personality according to the FFM as predictors of weight loss, quality of life, ${ }^{11,38}$ psychological stress, and wellbeing. ${ }^{38}$ Neither the Social Anxiety factors from the Dutch Personality Questionnaire (DPQ) nor neuroticism from the DPQ or the NEO-PI-R had predictive power for any outcome in these studies. ${ }^{11,38}$ Longitudinal studies that conducted follow-up of patients who underwent BS have indicated a reduction in neuroticism scores after surgery. ${ }^{11,36}$ It is possible that these findings reflect this change, although the small sample size in one of these studies should be taken into account.

When interpreting the findings of personality characteristics or PD as predictors of the results of BS, it must be considered that the samples of the studies reviewed all comprised participants who had the indications for this surgical procedure. This implies a sampling bias, since it is possible that participants with severe personality symptoms or disorders were refused the procedure or were given some other treatment prior to BS. As such, the severity of pathology would have been considered during clinical assessment for referral of patients for BS, since it interferes in patients' capacity for discernment, decision making, and compliance with guidance provided by the multidisciplinary team. ${ }^{57,58}$ The importance of predictive studies of personality related to non-adaptive or risky eating behaviors and surgical complications should also be highlighted.

\section{Changes in personality traits or disorders after bariatric surgery}

Four of the 16 studies reviewed attempted to understand changes to personality traits or disorders between preoperative and postoperative periods (Table 4). One of these ${ }^{29}$ assessed changes in the prevalence of PD and the other three $11,35,36$ investigated changes in the characteristics of personality assessed by the FFM. 
Only one study ${ }^{29}$ analyzed changes in the prevalence of mental disorders over time. The reason that researchers have invested little in studying personality psychopathology is possibly that they consider it to be a construct that is more stable over time, with less flexible and more pervasive patterns, ${ }^{23}$ that would be less likely to change, in addition to the need for large samples (as mentioned above).

In contrast with what was expected, Lier et al. ${ }^{29}$ reported a reduction in general personality psychopathology 1 year after the surgical procedure, particularly in avoidant PD. Since BS is a major procedure that results in significant changes to the physical appearance of patients, who report improved self-esteem and reduced anxiety, ${ }^{19,43}$ and bearing in mind the characteristics of avoidant PD (increased sensitivity to criticism, fear of ridicule, feelings of inferiority, avoidance of intimacy, among others), it might be expected that this pathology could be resolved.

The study investigating change in the prevalence of PD reviewed here ${ }^{29}$ indicated that there were more patients with PD from Cluster C (avoidant PD, dependent PD, and obsessive-compulsive PD) at preoperative assessment, whereas other studies have detected a higher incidence of patients with PD from Cluster B (especially borderline $P D$, histrionic $P D$, and narcissistic PD)..$^{21,40}$

With regard to changes in personality traits, specifically the neuroticism factor, one study ${ }^{35}$ reported no changes and two studies ${ }^{11,36}$ exhibited a significant reduction from the preoperative to postoperative periods (at 12 and 24 months, respectively). High scores for the neuroticism factor are related to emotional instability, susceptibility to anxiety, rage, depression, and impulsive acts. ${ }^{59}$ According to the studies analyzed, it appears that there is a tendency towards better emotional stability after the surgical procedure, which could be associated with the metabolic changes related to surgery. One study found that a reduction in markers of inflammatory processes (interleukin- 6 and high sensitivity C-reactive protein) mediated the reduction in scores for anxiety and depression. ${ }^{36}$

The extraversion factor increased in one of the studies $^{35}$ and the social anxiety factor from the DPQ reduced after the surgical procedure. Although one of the studies did not detect this change, it is possible that undergoing the surgery, and especially the weight reduction and improvement in mood symptoms, make people more likely to engage in a greater number of social relationships because they feel more confident and have higher self-esteem.

The factors conscientiousness, agreeableness, and openness to experience were only investigated in one of the studies. ${ }^{35}$ The authors observed an increase in conscientiousness and agreeableness, but not in openness to experience.

Table 4 - Studies that investigated changes in personality traits or disorders over time

\begin{tabular}{|c|c|c|c|c|c|c|c|}
\hline Article & Sample & $\begin{array}{l}\text { Mean age } \\
\text { at TO (SD) }\end{array}$ & $\begin{array}{l}\text { Mean BMI } \\
\text { at TO (SD) }\end{array}$ & $\begin{array}{l}\text { Personality } \\
\text { assessment }\end{array}$ & $\begin{array}{l}\text { Assessment } \\
\text { times (in } \\
\text { months) }\end{array}$ & $\begin{array}{l}\text { Outcome } \\
\text { variable }\end{array}$ & Main findings \\
\hline $\begin{array}{l}\text { da Silva \& } \\
\text { Maia }^{35}\end{array}$ & 30 & $39.17(8.81)$ & NI & NEO-FFI & $\begin{array}{l}\text { T0: NI } \\
\text { T1: } 6 \\
\text { T2: } 12\end{array}$ & $\begin{array}{l}\text { Changes to } \\
\text { factors of } \\
\text { NEO-FFI }\end{array}$ & $\begin{array}{l}\text { Significant increase in dimensions } \\
\mathrm{C}, \mathrm{E} \text {, and } \mathrm{AG} \text { from TO to T1 and } \\
\text { T0 to T2. N and O exhibited } \\
\text { significant differences between the } \\
\text { different assessment times. }\end{array}$ \\
\hline $\begin{array}{l}\text { Capuron, } \\
\text { et al. }{ }^{36}\end{array}$ & $\begin{array}{l}101 \text { (70 at } \\
12 \text { months) }\end{array}$ & $37.8(11.2)$ & $48.8(9.2)$ & $\begin{array}{l}\text { NEO-PI-R (N } \\
\text { and E scales) }\end{array}$ & $\begin{array}{l}\text { T0: NI } \\
\text { T1: } 12\end{array}$ & $\begin{array}{l}\text { Changes to } \\
\text { factors of } N \\
\text { and } E\end{array}$ & $\begin{array}{l}\text { N (anxiety, depression, self- } \\
\text { consciousness, and impulsivity) } \\
\text { was significantly lower at T1. } \\
\text { There was no significant change } \\
\text { in E. }\end{array}$ \\
\hline $\begin{array}{l}\text { van Hout } \\
\text { et al. }{ }^{11}\end{array}$ & 112 & $38.8(8.3)$ & $45.3(5.1)$ & $\begin{array}{l}\text { DPQ ( } \mathrm{N} \text { and } \\
\text { SA scales) }\end{array}$ & $\begin{array}{l}\text { T0: NI } \\
\text { T1: } 24\end{array}$ & $\begin{array}{l}\text { Changes to } \\
\mathrm{N} \text { and } \mathrm{SA}\end{array}$ & $\begin{array}{l}\mathrm{N} \text { and SA reduced from T0 to T1 } \\
\text { (but remained "average"). }\end{array}$ \\
\hline Lier et al. ${ }^{29}$ & $\begin{array}{l}87 \text { (141 at } \\
\text { preoperative } \\
\text { assessment) }\end{array}$ & $41.3(10.3)$ & $45.3(5.2)$ & $\begin{array}{l}\text { Short } \\
\text { Norwegian } \\
\text { version of } \\
\text { the SCID-II }\end{array}$ & $\begin{array}{l}\text { T0: NI } \\
\text { T1: } 12\end{array}$ & $\begin{array}{l}\text { Change in } \\
\text { prevalence } \\
\text { of PD }\end{array}$ & $\begin{array}{l}\text { Among } 87 \text { participants who } \\
\text { attended at T1, } 22 \% \text { had had } \\
\text { at least } 1 \text { PD at T0 (Cluster A: } \\
5 \% \text {; Cluster B: } 1 \% \text {; Cluster C: } \\
21 \%, 15 \% \text { avoidant PD). At T1, } \\
\text { the PD rate was } 8 \% \text { (Cluster A: } \\
1 \% ; \text { Cluster B: } 0 \% \text {; Cluster C: } \\
8 \%, 7 \% \text { avoidant PD. There was } \\
\text { a significant reduction in the } \\
\text { prevalence of any PD from T0 to } \\
\text { T1 and of avoidant PD. }\end{array}$ \\
\hline
\end{tabular}

$\mathrm{O}=$ openness to experience; $\mathrm{AG}=$ agreeableness; $\mathrm{SA}=$ social anxiety; $\mathrm{C}=$ conscientiousness; $\mathrm{SD}=$ standard deviation; $\mathrm{DPQ}=\mathrm{Dutch}$ Personality $\mathrm{Questionnaire}$; $\mathrm{E}=$ extraversion; $\mathrm{BMI}=$ body mass index; $\mathrm{N}=$ neuroticism; NEO-FFI = NEO Five Factor Inventory; NEO-PI-R = NEO Personality Inventory-Revised; NI = information not provided; SCID-II = Structured Clinical Interview for DSM-IV Axis II Personality Disorders; T0 = preoperative assessment; T1-T2 = postoperative assessments; PD = personality disorder. 
A meta-analysis that investigated normative changes in personality traits found that conscientiousness, extraversion, and emotional stability increase at the start of adulthood. Furthermore, it found that there was an increase in openness to experience in adolescence and a reduction in later life. ${ }^{60}$ It is therefore understood that there is a normal pattern of personality change that is age dependent. The articles analyzed in this review did not control for normal changes in personality, which could have increased the information available with relation to the impact that BS has on change in personality traits.

\section{Final comments}

This review analyzed articles with a longitudinal design that investigated outcomes of BS according to personality characteristics or disorders or assessed personality changes from preoperative to postoperative assessments. Although a very wide-ranging search of three different databases was conducted, it is possible that some relevant studies may have been omitted because of the inclusion criteria chosen or because they were listed on different databases.

The main findings of this review indicate that lesser and greater degrees of weight loss during the postoperative period are associated, respectively, with externalizing dysfunctions and characteristics of persistence that are present at preoperative assessment; while postoperative emotional or psychological disorders were associated with emotional or internalizing dysfunctions. After the surgery, it is possible that there are improvements in some $\mathrm{PD}$, indicated by reductions in their prevalence rates; easier social relations (increased extraversion scores), and greater emotional stability (reduction in scores for neuroticism). According to these findings, it is concluded that preoperative assessment of personality characteristics as part of predictive investigations and longitudinal follow-up of their characteristics and prevalence can help with understanding the different surgical prognoses. It should be highlighted that greater investment is needed in studies of outcomes beyond those restricted to issues of weight.

\section{Acknowledgements}

We are especially grateful to Dr. Eduardo Remor for his help providing suggestions and material for this review. We are also grateful for financial support from Fundo de Incentivo à Pesquisa - Hospital de Clínicas de Porto Alegre (FIPE-HCPA), Coordenação de Aperfeiçoamento de Pessoal de Nível Superior (CAPES) (2 doctoral bursaries), and Conselho Nacional de Desenvolvimento Científico e Tecnológico (CNPq) (1 master's scholarship and 1 research productivity grant, 1D).

\section{Disclosure}

No conflicts of interest declared concerning the publication of this article.

\section{References}

1. Adams TD, Pendleton RC, Strong MB, Kolotkin RL, Walker JM, Litwin SE, et al. Health outcomes of gastric bypass patients compared to nonsurgical, nonintervened severely obese. Obesity (Silver Spring). 2010;18:121-30.

2. Brasil, Conselho Federal de Medicina (CFM). Resolução CFM no 2131/2015. DiárioOficialdaUnião,13janeiro2016. https://sistemas. cfm.org.br/normas/visualizar/resolucoes/BR/2015/2131

3. Ramos AC. Brazil looking for completing his space in bariatric surgery. Arq Bras Cir Dig. 2014;27:1.

4. Sociedade Brasileira de Cirurgia Bariátrica e Metabólica (SBCBM) Residência médica em cirurgia bariátrica pode reduzir as filas dos hospitais do sistema público de saúde [Internet]. 2015 [cited 2015Feb 5]. sbcbm.org.br/wordpress/residencia-medicaem-cirurgia-bariatrica-pode-reduzir-as-filas-dos-hospitais-dosistema-publico-de-saude/

5. Ballantyne GH. Measuring outcomes following bariatric surgery: weight loss parameters, improvement in co-morbid conditions, change in quality of life and patient satisfaction. Obes Surg. 2003; 13:954-64.

6. Oria $\mathrm{HE}$, Moorehead MK. Bariatric analysis and reporting outcome system (BAROS). Obes Surg. 1998;8:487-99.

7. Dalcanale L, Oliveira CP, Faintuch J, Nogueira MA, Rondó P, Lima $\mathrm{VM}$, et al. Long-term nutritional outcome after gastric bypass. Obes Surg. 2010;20:181-7.

8. Magro DO, Geloneze B, Delfini R, Pareja BC, Callejas F, Pareja JC. Long-term weight regain after gastric bypass: a 5-year prospective study. Obes Surg. 2008;18:648-51.

9. Bastos EC, Barbosa EM, Soriano GM, dos Santos EA, Vasconcelos SM. Determinants of weight regain after bariatric surgery. Arq Bras Cir Dig. 2013;26:26-32.

10. Hsu LK, Benotti PN, Dwyer J, Roberts SB, Saltzman E, Shikora S, et al. Nonsurgical factors that influence the outcome of bariatric surgery: a review. Psychosom Med. 1998;60:338-46.

11. van Hout GCM, Hagendoren CA, Verschure SK, van Heck GL. Psychosocial predictors of success after vertical banded gastroplasty. Obes Surg. 2009;19:701-7.

12. Agüera Z, García-Ruiz-de-Gordejuela A, Vilarrasa N, Sanchez I, Baño M, Camacho $L$, et al. Psychological and personality predictors of weight loss and comorbid metabolic changes after bariatric surgery. Eur Eat Disord Rev. 2015;23:509-16.

13. Lanyon RI, Maxwell BM. Predictors of outcome after gastric bypass surgery. Obes Surg. 2007;17:321-8.

14. de Panfilis C, Cero S, Torre M, Salvatore P, Dall'Aglio E, Adorni A, et al. Utility of the temperament and character inventory (TCI) in outcome prediction of laparoscopic adjustable gastric banding: preliminary report. Obes Surg. 2006;16:842-7.

15. Duarte-Guerra LS, Coêlho BM, Santo MA, Wang YP. Psychiatric disorders among obese patients seeking bariatric surgery: results of structured clinical interviews. Obes Surg. 2014;25:830-7.

16. Lier HO, Biringer E, Stubhaug B, Tangen T. Prevalence of psychiatric disorders before and 1 year after bariatric surgery: the role of shame in maintenance of psychiatric disorders in patients undergoing bariatric surgery. Nord J Psychiatry. 2013;67:89-96.

17. Greenberg I, Perna F, Kaplan M, Sullivan MA. Behavioral and psychological factors in the assessment and treatment of obesity surgery patients. Obes Res. 2005;13:244-9.

18. Oliveira JHA de, Yoshida EMP. Avaliação psicológica de obesos grau iii antes e depois de cirurgia bariátrica. Psicol Reflex Crit. 2009;22:12-9. 
19. Almeida SS, Zanatta DP, Rezende FF. Imagem corporal, ansiedade e depressão em pacientes obesos submetidos à cirurgia bariátrica. Estud Psicol (Natal). 2012;17:153-60.

20. Castellini G, Godini L, Amedei SG, Faravelli C, Lucchese M, Ricca V. Psychological effects and outcome predictors of three bariatric surgery interventions: a 1-year follow-up study. Eat Weight Disord. 2014;19:217-24.

21. de Panfilis C, Generali I, Dall'Aglio E, Marchesi F, Ossola P, Marchesi C. Temperament and one-year outcome of gastric bypass for severe obesity. Surg Obes Relat Dis. 2014;10:144-8.

22. Kalarchian MA, Marcus MD, Levine MD, Soulakova JN, Courcoulas AP, Wisinski MS. Relationship of psychiatric disorders to 6-month outcomes after gastric bypass. Surg Obes Relat Dis. 2008;4:544-9.

23. Associação Americana de Psiquiatria. Manual Diagnóstico e Estatístico de Transtornos Mentais, $5^{a}$ edição (DSM-5). Porto Alegre: Artmed; 2014.

24. Cloninger CR, Svrakic DM, Przybech TR. A psychobiological model of temperament and character Arch Gen Psychiatry. 1993;50:975-90.

25. McCrae RR, Costa PT Jr. Personality trait structure as a human universal. Am Psychol. 1997;52:509-16.

26. McCrae RR, Costa PT Jr, Ostendorf F, Angleitner A, Hrebícková M, Avia MD, et al. Nature over nurture: temperament, personality, and life span development. J Pers Soc Psychol. 2000;78:173-86.

27. Roberts BW, Wood D, Smith JL. Evaluating five factor theory and social investment perspectives on personality trait development. J Res Pers. 2005;39:166-84.

28. Liberati A, Altman DG, Tetzlaff J, Mulrow C, Gøtzsche PC, Ioannidis JP, et al. The PRISMA statement for reporting systematic reviews and meta-analyses of studies that evaluate health care interventions: explanation and elaboration J Clin Epidemiol. 2009;62:e1-34.

29. Lier HO, Biringer E, Hove O, Stubhaug B, Tangen T. Quality of life among patients undergoing bariatric surgery: associations with mental health- A 1 year follow-up study of bariatric surgery patients. Health Qual Life Outcomes. 2011;9:79.

30. García-Llana H, Remor E, Del Peso G, Selgas R. The role of depression, anxiety, stress and adherence to treatment in dialysis patients' health-related quality of life: a systematic review of the literature. Nefrologia. 2014;34:637-57.

31. Berra S, Elorza-Ricart JM, Estrada MD, Sánchez E. [A tool (corrected) for the critical appraisal of epidemiological crosssectional studies]. Gac Sanit. 2008;22:492-7.

32. Marek RJ, Tarescavage AM, Ben-Porath YS, Ashton K, Merrell Rish J, Heinberg LJ. Using presurgical psychological testing to predict 1-year appointment adherence and weight loss in bariatric surgery patients: predictive validity and methodological considerations. Surg Obes Relat Dis. 2015;11:1171-81.

33. Gordon PC, Sallet JA, Sallet PC. The impact of temperament and character inventory personality traits on long-term outcome of roux-en-y gastric bypass. Obes Surg. 2014;24:1647-55.

34. Marek RJ, Ben-Porath YS, Merrell J, Ashton K, Heinberg LJ. Predicting one and three month postoperative somatic concerns, psychological distress, and maladaptive eating behaviors in bariatric surgery candidates with the Minnesota multiphasic personality inventory-2 restructured form (MMPI-2-RF). Obes Surg. 2014;24:631-9.

35. da Silva SS, Maia Ada C. Psychological and health comorbidities before and after bariatric surgery: a longitudinal study. Trends Psychiary Psychother. 2013;35:264-71.

36. Capuron L, Poitou C, Machaux-Tholliez D, Frochot V, Bouillot JL, Basdevant $A$, et al. Relationship between adiposity, emotional status and eating behaviour in obese women: role of inflammation. Psychol Med. 2011;41:1517-28.

37. Belanger SB, Wechsler FS, Nademin ME, Virden TB 3rd. Predicting outcome of gastric bypass surgery utilizing personality scale elevations, psychosocial factors, and diagnostic group membership. Obes Surg. 2010;20:1361-71.

38. Canetti L, Berry EM, Elizur Y. Psychosocial predictors of weight loss and psychological adjustment following bariatric surgery and a weight-loss program: the mediating role of emotional eating. Int J Eat Disord. 2009;42:109-17.

39. Bannen MA, Lambert PJ, Gustafson HL, Mathiason MA, Larson CJ, Kothari SN. Use of the Minnesota multiphasic personality inventory-2 to identify challenging-to-manage bariatric patients: efforts to promote success in all patients. Bariatr Nurs Surg Patient Care. 2008;3:211-6.
40. Pontiroli $A E$, Fossati A, Vedani P, Fiorilli M, Folli F, Paganelli M, et al. Post-surgery adherence to scheduled visits and compliance, more than personality disorders, predict outcome of bariatric restrictive surgery in morbidly obese patients. Obes Surg. 2007;17:1492-7.

41. Leombruni P, Piero A, Dosio D, Novelli A, Abbate-Daga G, Morino $M$, et al. Psychological predictors of outcome in vertical banded gastroplasty: a 6 months prospective pilot study. Obes Surg. 2007;17:941-8.

42. van Hout GC, Fortuin FA, Pelle AJ, van Heck GL. Psychosocial functioning, personality, and body image following vertical banded gastroplasty. Obes Surg. 2008;18:115-20.

43. Burgmer $R$, Legenbauer $T$, Müller $A$, de Zwaan $M$, Fischer $C$, Herpertz S. Psychological outcome 4 years after restrictive bariatric surgery. Obes Surg. 2014;24:1670-8.

44. Silva MO, Araújo MSM. Desordens no comportamento alimentar antes e após a cirurgia de bypass gástrico em um hospital público. Nutrire Rev Soc Bras Aliment Nutr. 2014;39:68-83.

45. Brunault $P$, Jacobi D, Miknius V, Bourbao-Tournois C, Huten N, Gaillard $P$, et al. High preoperative depression, phobic anxiety, and binge eating scores and low medium-term weight loss in sleeve gastrectomy obese patients: a preliminary cohort study. Psychosomatics. 2012;53:363-70.

46. World Health Organization (WHO). Global health Observatory data repository [Internet]. 2016 [cited 2016 Jun 22]. apps.who. int/gho/data/node.main.A900A?lang=en

47. Baptista MN, Baptista ASD, Vargas JF. Depressão e qualidade de vida em uma amostra brasileira de obesos mórbidos. Aval Psicol. 2008; 7:235-47.

48. Cambi MPC, Marchesini SD. Recuperei peso. Por quê? Curitiba: Editora CRV; 2014.

49. Lier HO, Biringer E, Stubhaug B, Eriksen HR, Tangen T. Psychiatric disorders and participation in pre- and postoperative counselling groups in bariatric surgery patients. Obes Surg. 2011;21:730-7.

50. Greene RL. The MMPI-2: an interpretive manual. 2nd ed. Needham Heights: Allyn \& Bacon; 2000.

51. Tellegen A, Ben-Porath YS. The Minnesota multiphasic personality inventory-2 restructured form (MMPI-2-RF): technical manual. Minneapolis: University of Minnesota; 2008/2011.

52. Ben-Porath YS, Tellegen A. The Minnesota multiphasic personality inventory-2 restructured form (MMPI-2-RF): manual for administration, scoring, and interpretation. Minneapolis: University of Minnesota; 2008/2011.

53. Hayden MJ, Murphy KD, Brown WA, O'Brien PE. Axis I disorders in adjustable gastric band patients: the relationship between psychopathology and weight loss. Obes Surg. 2014;24:1469-75.

54. Wadden TA, Faulconbridge LF, Jones-Corneille LR, Sarwer DB, Fabricatore AN, Thomas JG, et al. Binge eating disorder and the outcome of bariatric surgery at one year: a prospective, observational study. Obesity (Silver Spring). 2011;19:1220-8.

55. de Man Lapidoth J, Ghaderi A, Norring C. Binge eating in surgical weight-loss treatments. Long-term associations with weight loss, health related quality of life (HRQL), and psychopathology. Eat Weight Disord. 2011;16:e263-9.

56. Achenbach TM. Manual for the child behavior checklist/6-18 and 2001 profile. Burlington: University of Vermont; 2001.

57. Dziurowicz-Kozlowska AH, Wierzbicki Z, Lisik W, Wasiak D, Kosieradzki M. The objective of psychological evaluation in the process of qualifying candidates for bariatric surgery. Obes Surg. 2006;16:196-202.

58. Herpertz S, Kielmann R, Wolf AM, Hebebrand J, Senf W. Do psychosocial variables predict weight loss or mental health after obesity surgery? A systematic review. Obes Res. 2004;12:1554-69.

59. Widiger TA, Trull TJ. Personality and psychopathology: an application of the five-factor model. J Pers. 1992;60:363-93.

60. Roberts BW, Walton KE, Viechtbauer W. Patterns of mean-level change in personality traits across the life course: a meta-analysis of longitudinal studies. Psychol Bull. 2006;132:1-25.

\section{Correspondence:}

Suelen Bordignon

Rua Ramiro Barcelos, 2600, sala 119, Santana

90035003 - Porto Alegre, RS - Brazil

Tel. : +55 (51) 3308.5475

E-mail: bordignon.suelen@gmail.com 